\title{
Dietary supplementation with oregano essential oil and monensin in combination is antagonistic to growth performance of yearling Holstein bulls
}

\author{
Jianping Wu, ${ }^{1,2,3}$ Yan Bai, ${ }^{1,2 *}$ Xia Lang, ${ }^{2,4}$ Cailian Wang, ${ }^{2,4}$ Xiaolei Shi, ${ }^{5}$ David P. Casper, ${ }^{6}$ Liping Zhang, ${ }^{5}$ \\ Haibo Liu, ${ }^{7}$ Ting Liu, ${ }^{5}$ Xuyin Gong, ${ }^{2,4}$ Tingyu Liang, ${ }^{3}$ and Rui Zhang ${ }^{5}$ \\ ${ }_{1}^{1}$ Gansu Academy of Agricultural Science, No. 1 Agricultural Academy Village Anning, Lanzhou, Gansu, 730070, P. R. China \\ ${ }^{2}$ Key Laboratory for Sheep, Goat, and Cattle Germplasm and Straw Feed in Gansu Province, No. 1 Agricultural Academy Village Anning, \\ Lanzhou, Gansu 730030, P. R. China \\ ${ }^{3}$ Institute of Rural Development, Northwest Normal University, No. 967 East Street Anning, Lanzhou, Gansu 730070, P. R. China \\ ${ }^{4}$ Animal Husbandry, Pasture, and Green Agriculture Institute, Gansu Academy of Agricultural Sciences, No. 1 Agricultural Academy Village Anning, \\ Lanzhou, Gansu 730070, P. R. China \\ ${ }^{5}$ Faculty of Animal Science and Technology, Gansu Agricultural University, No. 1 Yingmen Village Anning, Lanzhou, Gansu 730070, P. R. China \\ ${ }^{6}$ Casper's Calf Ranch LLC, Freeport, IL 61032 \\ ${ }^{7}$ Institute of Agricultural and Economic Information, Gansu Academy of Agricultural Sciences, No. 1 Agricultural Academy Village Anning, Lanzhou, \\ Gansu 730030, P. R. China
}

\section{ABSTRACT}

Our previous work indicated that feeding oregano essential oil (OEO) in combination with monensin (MON) may not be mutually beneficial to dairy calf growth performance. To evaluate this observation further, a 240-d long-term growth experiment was conducted using 12 young growing Holstein bulls using a $2 \times 2$ factorial treatment arrangement. Main factors were $\mathrm{OEO}$ and $\mathrm{MON}$ arranged in 4 individual treatments: (1) ration fed without OEO or MON (control), (2) OEO fed at $26 \mathrm{mg} / \mathrm{kg}$ of dry matter (DM), (3) MON fed at $25 \mathrm{mg} / \mathrm{kg}$ of DM, and (4) OEO and MON fed in combination $(\mathrm{OEO}+\mathrm{MON})$. Holstein bulls were $70 \mathrm{~d}$ of age and similar in body weight (BW; $93.3 \pm$ $4.54 \mathrm{~kg}$ ) and individually fed for $240 \mathrm{~d}$. The targeted feeding rates of OEO and MON were blended into 200 $\mathrm{g}$ of concentrate and top dressed each morning to a corn stalklage-based ration. Body weights, frame measurements, and blood samples were collected monthly. Interactions of OEO by MON were detected for BW, BW gain, average daily gain, and a trend for feed conversion. Bulls fed OEO or MON demonstrated greater final $\mathrm{BW}(368,385,381$, and $358 \mathrm{~kg}$ for control, OEO, $\mathrm{MON}$, and $\mathrm{OEO}+\mathrm{MON}$, respectively), and BW gains $(278,292,285$, and $265 \mathrm{~kg})$ and average daily gain $(1.16$, $1.22,1.19,1.11 \mathrm{~kg} / \mathrm{d}$ ) were greatest for bulls fed OEO or MON compared with bulls fed OEO+MON; bulls

Received January 16, 2020.

Accepted April 29, 2020.

*Corresponding author: baiyan-baiyan@163.com fed the control were intermediate and similar to bulls fed MON. Intake of DM was greater for bulls fed OEO $(6.55,6.99,6.60$, and $6.42 \mathrm{~kg} / \mathrm{d})$ compared with bulls fed remaining treatments. Frame growth gain measurements for heart girth, abdominal girth, withers height, body length, and cannon bone circumference were similar for bulls fed all treatments. Serum triglyceride $(0.23,0.25,0.28$, and $0.24 \mathrm{mmol} / \mathrm{L})$ concentrations were greater for bulls fed MON compared with bulls fed the control and OEO+MON, and bulls fed OEO were intermediate and similar. Cholesterol $(2.06,2.29$, 2.20 , and $2.07 \mathrm{mmol} / \mathrm{L}$ ) concentrations were greater for bulls fed OEO compared with bulls fed the control and $\mathrm{OEO}+\mathrm{MON}$, and bulls fed MON were intermediate and similar. Serum antioxidant measurements were similar for bulls fed all treatments. Serum IgA, IgG, and IgM concentrations were similar for bulls fed all treatments. Feeding OEO or MON separately can improve growth performance of growing Holstein bulls. We do not know why the combination of OEO and MON is antagonistic to growth performance of Holstein bulls. However, these technologies should not be fed in combination to growing dairy cattle.

Key words: calves, growth, Holstein, oregano essential oil, monensin

\section{INTRODUCTION}

An increasing population combined with an increasing economic wealth (i.e., China) has accelerated the demand for livestock milk, meat, and egg protein production (Alexandratos et al., 2012) at the same time as an increase in banning antibiotics and antibiotic growth promoters (AGP; OJEU, 2003). The World 
Health Organization (Van Boeckel et al., 2017) identified antibiotic resistance as a worldwide public health problem due to the link between animal-derived antibiotic-resistant bacteria and human health (van den Bogaard et al., 2000; Donabedian et al., 2003). Monensin $(\mathbf{M O N})$, an ionophore that can be used as an AGP to improve growth performance and feed conversion, is being banned as well due to AGP perceptions.

Thus, AGP alternatives for maintaining healthy livestock, along with enhancing production and production efficiency, are needed to alleviate public AGP and antibiotic resistance concerns (Reverter et al., 2014). Plant extracted (i.e., distillation) essential oils (EO) have attracted attention by inhibiting pathogenic microorganisms (Benchaar et al., 2008), while modulating ruminal fermentation similar to MON (Zhou et al., 2020). Specific EO are proposed as potential AGP replacements, and oregano essential oil (OEO) holds great potential to improve growth performance, feed conversion, and animal health while modulating ruminal fermentation. Synthetic antioxidants can be replaced by OEO (Al-Hijazeen, 2018) because strong antimicrobial and antioxidant activities are present due to high carvacrol or thymol concentrations (Burt, 2004; Lejonklev et al., 2016; Paraskevakis, 2018).

The EO have been identified as beneficial feed additives for improving animal health as well as promoting growth performance (Mugnaini et al., 2013; Dudko et al., 2018; Fugita et al., 2018). However, there are limited scientific data evaluating the long-term responses and benefits of feeding EO on growth performance and serum biochemical indicators in growing Holstein calves (Kolling et al., 2018). Inconsistent results have been demonstrated across studies, which may be explained by experimental method (in vitro vs. in vivo), experimental design (i.e., Latin square vs. continuous designs), or inclusion rates. A limited number of dairy calf and cow studies have evaluated EO efficacy on performance, rumen fermentation, and immune function (Tekippe et al., 2011; Hristov et al., 2013; Froehlich et al., 2017). One issue regarding the feeding of specific EO is determining the optimal feeding rate. Froehlich et al. (2017) demonstrated that lower than recommended feeding rates of an $\mathrm{EO}$ combination resulted in improved dairy calf growth performance, which suggests that previous EO studies may have fed too much EO that resulted in similar or reduced animal performance.

Our hypotheses were (1) that OEO would enhance animal growth performance by shifting ruminal fermentation to more propionate, similar to MON, and potentially improve serum biochemical and immunity measurements and (2) that growth performance as a result of feeding OEO and MON separately may not be mutually beneficial when fed in combination due to excessive propionate production. The experimental objectives were to evaluate the growth responses, feed conversion, frame measurements, serum biochemical, and immunity measurements of growing Holstein bulls fed OEO or MON as growth promoters separately or in combination.

\section{MATERIALS AND METHODS}

\section{Experimental Design and Treatments}

This study was conducted at the Lintao Huajia Animal Husbandry Co. Ltd., $100 \mathrm{~km}$ south of Lanzhou, Gansu Province, China. The experiment was conducted according to the Chinese Standards for the Use and Care of Research Animals (He et al., 2016). The experimental design, procedures, and methods were executed according to the protocols approved by the Administration of Affairs Concerning Experimental Animals (Ministry of Science and Technology of the People. R. China) via the Gansu Agricultural University Animal Care and Use Committee guidelines (approved ID: 2012-2-159). The 12 growing Holstein bulls used in this experiment were selected from a previous 0 to $70 \mathrm{~d}$ calfstarter study using 80 calves (Wu et al., 2020). Bulls were selected at $70 \mathrm{~d}$ of age based on BW and previous treatment. Bulls were blocked by BW and randomly assigned to 1 of 4 treatments using a randomized complete block design (Steele and Torrie, 1980) with a 2 $\times 2$ factorial arrangement of treatments. Main factors were OEO (without and with) and MON (without and with), which resulted in 4 treatments: (1) ration fed without OEO and MON (control), (2) $26 \mathrm{mg}$ of OEO/ $\mathrm{kg}$ ration of DM, (3) $25 \mathrm{mg}$ of $\mathrm{MON} / \mathrm{kg}$ ration of $\mathrm{DM}$, and (4) $26 \mathrm{mg}$ of $\mathrm{OEO}$ and $25 \mathrm{mg}$ of $\mathrm{MON} / \mathrm{kg}$ ration of DM fed in combination (OEO+MON). The OEO contained the same proprietary water soluble EO blend as Froehlich et al. (2017; carvacrol, caryophyllene, pcymete, cineole, terpinene, and thymol) at $1.3 \% \mathrm{OEO}$ from Origanum vulgare ssp. hirtum plants plus cobalt lactate and clinoptilolite as a feed-grade inert carrier (Ralco Inc., Rum-A-Fresh, Marshall, MN); the MON was supplied by Norvikon Biotechnology Co. Ltd. (Hunan, China) at a 10\% concentration. Both products were supplied as dry powders as a single manufactured lot. Treatments were individually weighed and hand mixed with $200 \mathrm{~g}$ of grain mix daily. Bull calves were fed a TMR consisting of corn stalklage and a grain mix with ration inclusion amounts changing monthly (Table 1) to meet or exceed the nutrient requirements of growing Holstein bulls (NRC, 2001) for an experimental period of $240 \mathrm{~d}$. 


\section{Management and Feeding}

The Holstein bull calves were individually housed in a $4.8-\mathrm{m} \times 3-\mathrm{m}$ wheat straw bedded pen with a $1.5 \mathrm{~m}$ fence to separate pens in a naturally open-sided wellventilated barn. Each pen had a $160 \times 40 \times 30 \mathrm{~cm}$ trough with a middle partition for one end to hold water and the other end for TMR. To avoid TMR intake from adjacent troughs, partitions were placed between troughs to prevent feed stealing and ensure experimental accuracy. Pens and troughs were thoroughly cleaned and disinfected before the start of the experiment.

Fresh TMR (Table 1) was fed to the bull calves 3 times daily at 0800, 1400, and $2000 \mathrm{~h}$. Feed was thoroughly mixed once daily using a TMR mixer (model 9JGW, Zhengzhou Leabon Machinery Equipment Col Ltd., Henan, China) and delivered using a mobile cart. The amount of TMR fed daily was adjusted to target a $10 \%$ TMR refusal so that individual intakes met or exceeded nutrient requirements for each feeding period per NRC recommendations (NRC, 2001). During the first 30-d period, alfalfa hay and calf starter were fed to aid in transitioning bulls from the previous calf starter study onto the corn silage based TMR. Refusals (orts) were collected every morning before the $0800 \mathrm{~h}$ feeding to ensure that fresh feed was supplied and available daily. Voluntary feed intake and orts for each bull calf was individually recorded on 3 consecutive days each week for the calculation of DMI. Bull calves had ad libitum access to fresh water at all times.

\section{Feed Analysis}

Samples of TMR and feed ingredients were collected once weekly and frozen immediately for storage at $-20^{\circ} \mathrm{C}$ until further analyses for nutritional composition. Feed samples were thawed at the end of the experiment and $4 \mathrm{wk}$ of samples were composited in a monthly sample for subsequent nutrient assays. Dry matter concentration of TMR samples was determined by forced air oven (model 101-19B Shinbae Industrial Co. Ltd., Shanghai, China) at $60^{\circ} \mathrm{C}$ for $48 \mathrm{~h}$ and ground through a mill (Foss 156 Tecator, Akutalstuku, Tokyo, Japan) with a 1-mm screen and stored for later analyses (AOAC International, 2019). Nutrient concentrations of DM (930.15), CP (990.03), NDF (2002.04) via A200 (Ankom Technology, Macedon, NY) using sulfite and Ankom's $\alpha$-amylase, ADF (973.18), fat (920.39), ash (942.05), Ca (985.01), and P (985.01) were analyzed according to standard AOAC International official meth-

Table 1. Ingredient composition and nutrient density of the TMR for the respective feeding periods, \% of DM

\begin{tabular}{|c|c|c|c|c|c|c|c|c|}
\hline \multirow[b]{2}{*}{ Item } & \multicolumn{8}{|c|}{ Experimental period, day (month) } \\
\hline & $\begin{array}{c}70-100 \\
(1)\end{array}$ & $\begin{array}{c}100-130 \\
(2)\end{array}$ & $\begin{array}{c}130-160 \\
(3)\end{array}$ & $\begin{array}{c}160-190 \\
(4)\end{array}$ & $\begin{array}{c}190-220 \\
(5)\end{array}$ & $\begin{array}{c}220-250 \\
(6)\end{array}$ & $\begin{array}{c}250-280 \\
(7)\end{array}$ & $\begin{array}{c}280-310 \\
(8)\end{array}$ \\
\hline \multicolumn{9}{|l|}{ Ingredient } \\
\hline Corn, ground & 26.20 & 26.20 & 26.20 & 27.60 & 27.60 & 28.00 & 28.00 & 29.20 \\
\hline Soybean meal, $48 \%$ CP & 3.60 & 3.60 & 3.60 & 3.20 & 3.20 & 2.80 & 2.80 & 2.80 \\
\hline Cottonseed meal & 4.80 & 4.80 & 4.80 & 3.60 & 3.60 & 3.60 & 3.60 & 2.80 \\
\hline Rapeseed meal & 3.60 & 3.60 & 3.60 & 3.60 & 3.60 & 3.60 & 3.60 & 3.20 \\
\hline Limestone & 0.60 & 0.60 & 0.60 & 0.60 & 0.60 & 0.60 & 0.60 & 0.60 \\
\hline Premix $^{1}$ & 0.40 & 0.40 & 0.40 & 0.40 & 0.40 & 0.40 & 0.40 & 0.40 \\
\hline Sodium bicarbonate & 0.40 & 0.40 & 0.40 & 0.40 & 0.40 & 0.40 & 0.40 & 0.40 \\
\hline Salt & 0.40 & 0.40 & 0.40 & 0.60 & 0.60 & 0.60 & 0.60 & 0.60 \\
\hline Yellow corn silage & 60 & 60 & 60 & 60 & 60 & 60 & 60 & 60 \\
\hline Alfalfa, $\mathrm{kg} / \mathrm{kg}$ of DM & 1 & - & - & - & - & - & - & - \\
\hline Starter, kg/kg of DM & 1 & - & - & - & - & - & - & - \\
\hline \multicolumn{9}{|l|}{ Nutrient density } \\
\hline DM, $\%$ & 61.3 & 62.6 & 62.5 & 63.9 & 62.6 & 61.5 & 63.9 & 59.7 \\
\hline $\mathrm{OM}^{2} \%$ of $\mathrm{DM}$ & 94.0 & 93.6 & 93.9 & 93.1 & 93.9 & 93.3 & 93.9 & 94.4 \\
\hline $\mathrm{CP}, \%$ of DM & 13.1 & 12.6 & 12.7 & 12.6 & 12.0 & 12.8 & 11.6 & 10.7 \\
\hline NDF, $\%$ of DM & 42.5 & 41.1 & 42.8 & 41.8 & 41.7 & 43.3 & 42.7 & 42.6 \\
\hline $\mathrm{ADF}, \%$ of $\mathrm{DM}$ & 25.7 & 24.9 & 26.9 & 23.8 & 25.0 & 24.7 & 25.9 & 25.0 \\
\hline Fat, $\%$ of DM & 1.86 & 1.86 & 1.85 & 1.83 & 1.91 & 1.81 & 1.79 & 1.78 \\
\hline $\mathrm{NFC},{ }^{3} \%$ of DM & 38.4 & 40.0 & 38.3 & 39.0 & 40.3 & 37.2 & 39.6 & 41.0 \\
\hline Ash, $\%$ of DM & 4.12 & 4.45 & 4.34 & 4.77 & 4.06 & 4.87 & 4.30 & 3.90 \\
\hline $\mathrm{Ca}, \%$ of $\mathrm{DM}$ & 0.65 & 0.61 & 0.58 & 0.60 & 0.56 & 0.49 & 0.44 & 0.49 \\
\hline $\mathrm{P}, \%$ of $\mathrm{DM}$ & 0.32 & 0.37 & 0.34 & 0.36 & 0.34 & 0.35 & 0.33 & 0.34 \\
\hline
\end{tabular}

${ }^{1}$ Contained (per kg): 220,000 IU of vitamin A, 72,000 IU of vitamin $\mathrm{D}_{3}, 2,000 \mathrm{IU}$ of vitamin E, $830 \mathrm{mg}$ of Fe, $680 \mathrm{mg}$ of $\mathrm{Cu}, 710 \mathrm{mg}$ of $\mathrm{Mn}, 2,005$ $\mathrm{mg}$ of $\mathrm{Zn}, 0.3 \mathrm{mg}$ of Se, $42 \mathrm{mg}$ of I, and $12 \mathrm{mg}$ of Co.

${ }^{2} \mathrm{OM}=100-$ DM.

${ }^{3} \mathrm{NFC}=100-(\mathrm{CP}+\mathrm{NDF}+$ fat + ash $)$. 
ods of analysis (AOAC International, 2019). Organic matter concentration was calculated as 100 - ash (\%), and NFC was calculated as $100-\mathrm{CP}-\mathrm{NDF}$ - fat - ash (NRC, 2001) as an indirect estimate of starch content.

\section{Skeletal Measurements}

Skeletal measurements were taken approximately once monthly on d 70,100,130, 160, 190, 220, 250, 280, and 310 of age. Withers height (WH) was measured using a sliding scale height stick (I-Herdsman Machinery Co. Ltd., Zheng Zhou, China), body length (BL) was measured from the point of shoulder to ischial bone, heart girth (HG) was measured just behind the elbows around the chest, abdominal girth was measured as the maximum vertical circumference of the anterior hind leg abdomen, and cannon bone circumference was measured from horizontal circumference of the finest part of the left forefoot. The HG, abdominal girth, and cannon bone circumference were all measured using a measuring tape (Hoechstmass LLC., Sulzbach, FB, Germany). Body weight was measured using an electronic digital livestock scale (model XK3190-A12+E, Yaohua Weighing System Co. Ltd., Shanghai, China).

\section{Blood Sampling and Analysis}

Blood samples were collected via jugular venipuncture from each Holstein bull using $10-\mathrm{mL}$ vacutainer tubes without anticoagulant and an 18-gauge needle (Sanli Medical Technology Development Co. Ltd., Liuyang, Hunan, P. R. China) before the morning feeding on weigh days. Whole blood was centrifuged (TGL-16, Cence Ltd., Changsha, China) at 2,810 $\times g$ for $10 \mathrm{~min}$ at $20^{\circ} \mathrm{C}$. Serum was decanted into cryogenic vials (Corning Inc., Corning, NY) and frozen at $-80^{\circ} \mathrm{C}$ (ULT freezer model DW-86L828, Haier Biomedical, Zingdoo, China) for analyses to be conducted at a later date. Blood serum was thawed and analyzed via a 7020 automatic clinical biochemistry analyzer (Hitachi, Japan) by the Hunan Fengrui Biotechnology Co. Ltd. (Chang Sha, Hunan, China) using the manufacturer's kits for total serum protein, albumin (ALB), BUN, glucose, triglyceride (TG), total cholesterol, high density lipoprotein cholesterol (HDL), and low density lipoprotein cholesterol (LDL). Growth hormone, IGF-1, superoxide dismutase, glutathione, glutathione peroxidase, Catalase, total antioxidant capacity, IgA, IgG, and IgM were measured using ELISA kits (Wuhan Chundu Biotechnology Co. Ltd., Wuhan, China) using a microplate reader model ST-360 (Kehua Bio-Engineering Co., Ltd., Shanghai, China).

\section{Statistical Analyses}

Before statistical analysis, all data were checked for normality and outliers using the UNIVARIATE procedure of SAS (version 9.4, SAS Institute Inc., Cary, NC). The box and whisker plots and Shapiro-Wilk test were used to verify that data were normality distributed $(P$ $>0.10$ ). All data were then subjected to least squares ANOVA for a randomized complete block design with a $2 \times 2$ factorial arrangement of treatments (Steele and Torrie, 1980) as a repeated measure ANOVA using the MIXED procedure of SAS according to the following model:

$$
\begin{gathered}
Y_{h i j k}=\mu+B_{h}+O E O_{i}+M O N_{j}+D_{k} \\
+\left(O E O_{i} \times M O N_{j}\right)+\left(O E O_{i} \times D_{k}\right)+\left(M O N_{j} \times D_{k}\right) \\
+\left(O E O_{i} \times M O N_{j} \times D_{k}\right)+e_{h i j k},
\end{gathered}
$$

where $Y_{h i j k}=$ the dependent variable, $\mu=$ overall mean, $B_{h}=$ block $(h=1,2,3)$ by BW, $O E O_{i}=$ OEO main effect $(i=1$ or 2$) ; M O N_{j}=$ MON main effect $(j=1$ or 2$) ; D_{k}=$ study day $(k=70,100,130,160,190,220$, 250, 280,310); $O E O_{i} \times M O N_{j}=$ interaction of $O E O_{i}$ by $M O N_{j} ; O E O_{i} \times D_{k}=$ interaction of $O E O_{i}$ by day; $M O N_{j} \times D_{k}=$ interaction of $M O N_{j}$ by $D_{k}$; and $O E O_{i}$ $\times M O N_{j} \times D_{k}=$ interaction of $O E O_{i}$ by $M O N_{j}$ by $D_{k}$; and $e_{h i j k}=$ the residual error. Block was considered a random effect, and $O E O_{i}, M O N_{j}, D_{k}$ and interactions were considered fixed effects; $D_{k}$ was analyzed as a repeated measurement with an autoregressive covariance structure. Initial $d=70$ (period 0 ) starting values for each parameter were evaluated as a covariate, but the use of a covariate was found to be nonsignificant $(P$ $>0.15)$, and therefore was excluded from the model. Least squares means were separated by the PDIFF statement, which is the least significant difference method when the ANOVA F-test was significant for the OEO by MON interaction. Differences among main effects and interactions were considered significant at $P$ $\leq 0.05$ and trends at $0.05<P \leq 0.10$.

One immediate study concern may be the small number of animals used due to limitations of available facilities to determine BW and ADG differences. The lack of larger facilities (i.e., more pens) prevented additional replication that would be possible if conducting a short-term study (i.e., Latin square). The use of repeated measures over time met one of the experiment's objectives and increased the statistical precision (Faul, et al., 2007). A retrospective power and sample-size evaluation using the data from the study revealed that the experimental power was $>80 \%$ due to the magnitude of differences observed and the resulting standard 
Table 2. Growth performance for young Holstein dairy bulls fed a TMR without or with oregano essential oil (OEO) and without or with monensin $(\mathrm{MON})$

\begin{tabular}{|c|c|c|c|c|c|c|c|c|}
\hline \multirow[b]{2}{*}{ Measurement } & \multicolumn{4}{|c|}{ Treatment } & \multirow[b]{2}{*}{ SEM } & \multicolumn{3}{|c|}{$P$-value ${ }^{1}$} \\
\hline & $\mathrm{CON}$ & $\mathrm{OEO}$ & MON & $\mathrm{OEO}+\mathrm{MON}$ & & OEO & MON & $\mathrm{OEO} \times \mathrm{MON}$ \\
\hline Initial BW, $\mathrm{kg}$ & $90^{\mathrm{b}}$ & $94^{\mathrm{ab}}$ & $96^{\mathrm{a}}$ & $92^{\mathrm{ab}}$ & 2.09 & 0.94 & 0.26 & 0.10 \\
\hline Final BW, kg & $368^{\mathrm{b}}$ & $385^{\mathrm{a}}$ & $381^{\mathrm{a}}$ & $358^{\mathrm{b}}$ & 7.09 & 0.68 & 0.35 & 0.02 \\
\hline $\mathrm{BW}^{2}$ gain, $\mathrm{kg}$ & $278^{\mathrm{b}}$ & $292^{\mathrm{a}}$ & $285^{\mathrm{ab}}$ & $265^{\mathrm{c}}$ & 6.32 & 0.66 & 0.17 & 0.03 \\
\hline $\mathrm{ADG}, \mathrm{kg} / \mathrm{d}$ & $1.16^{\mathrm{b}}$ & $1.22^{\mathrm{a}}$ & $1.19^{\mathrm{ab}}$ & $1.11^{\mathrm{c}}$ & 0.02 & 0.66 & 0.13 & 0.02 \\
\hline
\end{tabular}

${ }^{\mathrm{a}-\mathrm{c}}$ Means with unlike superscripts in the same row differ, $P<0.05$

${ }^{1} P$-value of main effects of $26 \mathrm{mg} / \mathrm{kg}$ OEO, $25 \mathrm{mg} / \mathrm{kg}$ MON, or the interaction of main effects.

${ }^{2}$ Body weights were collected on $70,100,130,160,190,220,250,280$, and $310 \mathrm{~d}$ of age.

${ }^{3}$ The DMI exhibited an interaction of OEO $\times$ MON $\times$ month, $P<0.10$.

error of the mean (Faul et al., 2007). Based on power and sample size calculations for repeated measurement experiments, confidence is high in the results.

\section{RESULTS}

\section{Ration Nutrient Composition}

The nutrient composition of the TMR for each monthly period of the 8 mo experiment met or exceeded formulation specifications (Table 1). These nutrient concentrations meet or exceed the recommended nutrient requirements for growing Holstein bull calves (NRC, 2001). The addition of alfalfa hay and calf starter during the first feeding period was used to facilitate a smooth transition from a calf starter or grower ration to a TMR that contained only corn stalklage and grain $\operatorname{mix}$ (Table 1).

\section{Growth Performance}

The starting BW for the Holstein bull calves on $\mathrm{d}$ 70 was similar among treatments $(P=0.10)$ at 93.3 $\pm 4.54 \mathrm{~kg}$ (Table 2) The OEO $\times$ MON interaction was significant $(P<0.03)$ for final $\mathrm{BW}, \mathrm{BW}$ gain, and ADG. Holstein bull calves fed OEO or MON demonstrated greater $(P<0.02) \mathrm{BW}$ at the end of the 240-d experiment compared with bulls fed the control and OEO+MON. Bulls fed OEO or MON during the course of the 240-d experiment demonstrated consistent improvements in BW gain compared with bulls fed the control. However, due to small nonsignificant differences in starting BW, bulls fed OEO demonstrated greater BW gains and ADG than bulls fed the control, and bulls fed MON were intermediate and similar $(P$ $>0.10)$ compared with bulls fed the control; bulls fed OEO+MON demonstrated reduced $(P<0.05)$ BW gain and ADG compared with bulls fed all other treatments (i.e., the control, OEO, and MON). The reduced growth performance for bulls fed OEO+MON took time to develop compared with bulls fed OEO or MON and was similar to bulls fed the control by the end of the study. Thus, any performance improvements achieved by feeding OEO or MON separately were canceled by feeding $\mathrm{OEO}+\mathrm{MON}$ in combination. Bulls fed the OEO+MON were slow to start, with the numerically lowest ADG in the first and last month of the study (data not shown). This observation supports the poorer BW gain and ADG observed during the experiment (Table 2).

Holstein bull calves fed OEO demonstrated greater $(P<0.03)$ DMI during the 240-d study compared with bulls fed the remaining treatments. The OEO by MON interaction demonstrated a tendency $(P<0.10)$ for feed conversion, which resulted in bulls fed MON with a greater $(P<0.05)$ feed conversion compared with bulls fed the remaining treatments. Bulls fed OEO were numerically greater in DMI consistently during the early periods of the experiment, but the differences became significant only during periods 7 and 8 of the experiment (data not shown, OEO $\times$ MON $\times$ month interaction, $P<0.10$ ) compared with bulls fed the remaining treatments.

\section{Frame Measurements}

Interactions $(P \leq 0.03)$ of OEO by MON were detected for final $\mathrm{HG}, \mathrm{WH}$, and $\mathrm{BL}$ measurements, and HG gain demonstrated a tendency $(P<0.09)$ for an OEO by MON interaction. Holstein bulls fed MON demonstrated greater $(P<0.05)$ final HG measurements compared with bulls fed the control and bulls fed OEO were intermediate and similar $(P>0.10)$; 
final HG measurements were lowest $(P<0.05)$ for bulls fed OEO+MON in combination compared with bulls fed other treatments. Due to small differences in initial HG measurements among treatments, HG gains were greater $(P<0.05)$ for bulls fed OEO or MON compared with bulls fed $\mathrm{OEO}+\mathrm{MON}$, and gains for bulls fed the control were intermediate and different $(P<0.05)$.

Holstein bull calves fed OEO or MON demonstrated greater $(P<0.05)$ final WH compared with bulls fed the control and OEO+MON. However, WH gains were similar $(P>0.05)$ for bulls fed all treatments and were not influenced $(P>0.35)$ by main effects of OEO or MON. Holstein bulls fed OEO or MON demonstrated greater $(P<0.05)$ final BL measurements compared with bulls fed OEO+MON, and bull calves fed the control were intermediate and similar $(P>0.05)$. However, $\mathrm{BL}$ gains were not influenced by the interaction of OEO by MON, and $\mathrm{OEO}$ or MON main effects were similar $(P>0.10)$ as well. The OEO or MON main effects demonstrated no differences $(P>0.10)$ on remaining frame measurements (Table 3 ).

\section{Serum Biochemical Measurements}

Total serum protein concentrations demonstrated $(P$ $<0.05)$ an OEO by MON interaction, and the main effect of OEO was a tendency $(P<0.08)$; total serum protein concentrations in bulls fed OEO, MON, and $\mathrm{OEO}+\mathrm{MON}$ were greater $(P<0.05)$ than those in bulls fed the control (Supplemental Table S1, https:/ /doi.org/10.3168/jds.2020-18211). The OEO by MON interaction was nonsignificant $(P>0.10)$ for final BUN, ALB, growth hormone, and IGF-1 concentrations, and the OEO or MON main effects were similar $(P>0.10)$.

No OEO by MON interactions were detected $(P>$ $0.10)$ for serum concentrations of glucose, HDL, and LDL measurements, and the OEO or MON effects were similar $(P>0.10$; Supplemental Table S2, https: //doi.org/10.3168/jds.2020-18211). Serum TG concentrations were greater $(P<0.05)$ for bulls fed MON compared with bulls fed the control and OEO+MON, and bulls fed OEO were intermediate and similar $(P$ $>0.05$ ). Serum cholesterol concentrations were greater $(P<0.05)$ for bulls fed OEO compared with bulls fed the control and OEO+MON, and bulls fed MON being intermediate and similar $(P>0.05)$. No differences due to the main effects of $\mathrm{OEO}$ or MON or the interaction of OEO by MON were detected $(P>0.10)$ among monthly time points for glucose, triglycerides, cholesterol, HDL, and LDL concentrations (data not shown).

No OEO by MON interactions were detected $(P$ $>0.10)$ for serum concentrations of super oxide dismutase, glutathione, glutathione peroxidase, catalase, and total antioxidant capacity measurements, and the OEO or MON main effects were similar $(P>0.10$; Supplemental Table S3, https://doi.org/10.3168/jds .2020-18211). No differences due to the main effects of $\mathrm{OEO}$ or MON or the OEO by MON interaction were

Table 3. Skeletal and frame growth measurements for young Holstein dairy bulls fed a TMR without or with oregano essential oil (OEO) and without or with monensin (MON)

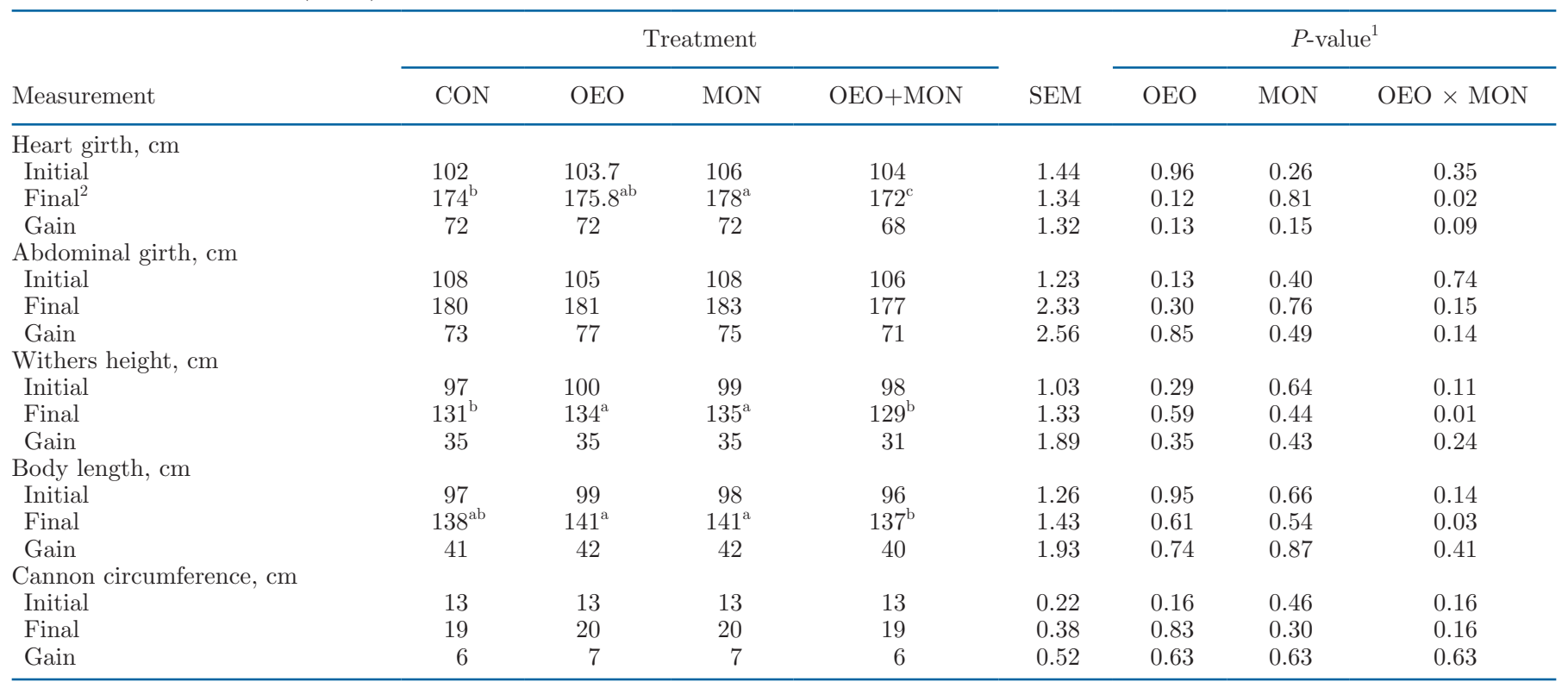

${ }^{\mathrm{a}-\mathrm{c}}$ Means with unlike superscripts in the same row differ, $P<0.05$

${ }^{1} P$-value of main effects of $26 \mathrm{mg} / \mathrm{kg}$ OEO, $25 \mathrm{mg} / \mathrm{kg} \mathrm{MON}$, or the interaction of main effects.

${ }^{2}$ Body frame measurements were collected on d 70, 100, 130, 160, 190, 220, 250, 280, and $310 \mathrm{~d}$ of age. 
detected $(P>0.10)$ among monthly time points for antioxidant measurements (data not shown).

No OEO by MON interactions were detected $(P>$ 0.10 ) for serum immune concentrations of $\operatorname{IgA}, \operatorname{IgG}$, and $\operatorname{IgM}$ and the main effect of OEO on IgG demonstrated a tendency $(P<0.10$; Supplemental Table S4, https://doi.org/10.3168/jds.2020-18211). No differences due to the main effects of OEO or MON or the OEO by MON interaction were detected $(P>0.10)$ among monthly time points for immune measurements (data not shown).

\section{DISCUSSION}

Some shortcomings in the literature are the use of short-term studies or Latin square designs to evaluate EO, which prevents responses developing with time to be measurable; therefore, we chose a long-term study (8 mo) with a minimum number of animals (due to facility limitations) without introducing confounding weather, season, feed supplies, and quality effects. The OEO by MON interaction was noteworthy for several key growth performance measurements, which was not expected based on the hypothesis. Response time may have been an issue; therefore, continuous trials with longer time periods than Latin squares should be considered in future studies.

The improvement in BW, BW gain, and ADG demonstrated in this study have been previously demonstrated when feeding OEO (Froehlich et al., 2017) or MON (Duffield et al., 2012) alone. These data demonstrate that feeding OEO can result in enhanced growth performance similar to MON. Benchaar et al. (2006) demonstrated similar growth performance improvements when feeding OEO or MON separately. Zhou et al. (2020) demonstrated that OEO can shift ruminal fermentation to increase propionate concentrations that would be similar to the shift in ruminal fermentation when feeding MON (Duffield et al., 2012).

In the current study, supplementation with OEO increased DMI. Benchaar et al. (2006) demonstrsated that supplementing an EO blend (containing thymol, eugenol, vanillin, and limonene) at rates of 2, 3, and 4 $\mathrm{g} / \mathrm{d}$ increased DMI when fed to beef cattle; however, in another experiment, dietary EO addition at inclusion rates of 2 and $4 \mathrm{~g} / \mathrm{d}$ increased feed efficiency, which is consistent with these data. Zhou et al. (2019) fed 4 and $7 \mathrm{~g} / \mathrm{d}$ of the same OEO product as this study to sheep and found improved DMI and feed efficiency, and Unal and Kocabagli (2014) reported that 250 and $500 \mathrm{ppm}$ of OEO improved feed efficiency. In contrast, several studies reported no DMI or feed efficiency responses when feeding an EO blend to growing beef cattle (Beauchemin and McGinn, 2006; Meyer, et al., 2009;
Rivaroli et al., 2017). Inconsistent DMI or feed efficiency responses have been observed when feeding OEO to dairy and beef cattle because DMI may be influenced by multiple factors, including body condition, management, climate, ingredients, ruminal propionate production, nutrient composition, physical, digestibility, and agronomic characteristics of feed (Hayirli et al., 2002; Oba and Allen, 2003). Palatability can be adversely affected when feeding a large dose of blended eugenol and cinnamaldehyde (Patra, 2012). It may be due to its compounds with phenolic structures (i.e., thymol and carvacrol) that are more effective as antimicrobials than other EO (Ultee, et al., 2002). Furthermore, the effect was more pronounced at lower doses than higher doses as time progressed (Khiaosa-ard and Zebeli, 2013). In contrast, OEO decreased feed efficiency for bulls, indicating regulation of ruminal microflora through the effects of ruminal fermentation patterns by the active components of oregano (mainly phenolic compounds of cravacrol and thymol, which make up $78-82 \%$ of the total oil; Adam et al., 1998). Therefore, oregano has the potential to improve DMI, depending on the EO type and dose (Patra, 2012).

A key unexpected finding is that the combination of feed additives OEO and MON decreased BW, BW gain, ADG, and feed conversion (Table 2), suggesting antagonism between these compounds. It is unknown why OEO in combination with MON was antagonistic to Holstein bull growth performance resulting in similar or reduced performance measurements compared with bulls fed the control. Ruminants have a complex ruminal microbial ecosystem, which is a dynamic balance that can be both synergistic and antagonistic between rumen microorganisms and host. Ration composition, ingredients, and feed processing may be a determining factor for various EO and combinations that cause vastly different responses to animal growth and efficiency. Ultee et al. (2002) reported that mode of action of hydroxyl substances in phenolic compounds are similar to ionophore mode of action by carrying ions and protons in and out through the cellular membrane. The bioactive compounds disrupt the cellular membrane lipid structure, inhibiting enzymatic and metabolic activities and resulting in cellular death. These potential dual-action modes that occur at the same time when feeding OEO and MON simultaneously may result in negative effects that would not occur when fed separately. The speculation is too much ruminal propionate production may be the result of both OEO and MON shifting ruminal fermentation. Propionate is a known appetite suppressant in cattle (Oba and Allen, 2003). The speculation is that both OEO and MON by shifting ruminal fermentation to more propionate may have resulted in too much propionate being produced 
at the expense of other VFA by both nutritional technologies that affected growth performance. However, the reduction in growth performance observed when feeding an $\mathrm{OEO}+\mathrm{MON}$ combination may explain why field responses to feeding OEO have been inconsistent because MON may have been present in the ration (MON is commonly fed to growing dairy cattle). To our knowledge, no long-term studies exist in the literature that feed OEO and MON in combination. A short-term study (Benchaar, 2020) that fed oregano oil to lactating dairy cows reported similar milk production and DMI to the control when fed OEO or MON alone, but an OEO and MON combination was not fed. However, Benchaar (2020) fed lactating dairy cows a combination of EO and MON using 4 cows in a $4 \times 4$ Latin square design with 28-d periods and reported similar milk production with no determinantal observations. However, this study (Benchaar, 2020) used limited cow numbers and short-term periods.

The lack of an additive or synergistic response observed in these data when feeding OEO in combination with MON on BW, BW gains, and ADG is consistent with studies using dairy cattle, beef cattle, and sheep. For example, Benchaar et al. (2006) reported that an EO mixture (unknown ingredients) fed at 2 and $4 \mathrm{~g} / \mathrm{d}$ to beef cattle resulted in similar performance measurements. Rivaroli et al. (2017) reported that 500 and 1,000 $\mathrm{mg} / \mathrm{kg}$ of DM of an EO blend (containing oregano, thymus, garlic, lemon, rosemary, eucalyptus, and sweet orange) fed for $120 \mathrm{~d}$ resulted in similar performance when fed to crossbred bulls. Furthermore, Unal and Kocabagli (2014) reported that dietary supplementation at 250 and $500 \mathrm{ppm}$ OEO (oregano) to lambs resulted in similar performance measurements, which agrees with Bampidis et al. (2005) and Simitzis et al. (2008). However, the data showed large differences between the results of numerous additives included in the diets of ruminants (Benchaar et al., 2008; Zhang et al., 2010). In contrast, Valero et al. (2014) demonstrated that feeding EO (containing ricinoleic acid) to crossbred bulls improved final $\mathrm{BW}$ weight, $\mathrm{ADG}$, and hot carcass weight. Calsamiglia et al. (2007) suggested that feeding lower EO inclusion rates favor beef over dairy production.

Thymol and carvacrol, the main OEO components, are known to demonstrate wide-spectrum antibacterial and antioxidant activities against gram-positive and gram-negative bacteria, implying a high likelihood of the ability to modulate ruminal fermentation (Castillejos et al., 2006; Calsamiglia et al., 2007; Bakkali et al., 2008). However, there can be a narrow inclusion rate range between optimal and toxic dosages. In addition, diverse EO types may have synergistic and antagonis- tic effects when used in combination (Calsamiglia et al., 2007). The literature is limited, but growing when evaluating OEO responses on DMI and feed efficiency of ruminants, but additional studies are needed under controlled long-term conditions.

Monensin feeding is often associated with reduction in DMI (Benchaar et al., 2006; Aderinboye et al., 2012), depending on diet composition and MON inclusion rate (Aderinboye et al., 2012). The improved feed efficiency with the addition of MON is attributed to a shift in ruminal fermentation to produce more propionic acid while decreasing acetic and butyric acid concentrations (Calsamiglia et al., 2007; Benchaar et al., 2008). In contrast, the current study showed that feeding MON to dairy bull calves did not decrease DMI, but did improve feed efficiency. There are many studies evaluating the efficiency of MON on DMI in ruminants. The lack of responses in DMI when feeding MON agrees with Plaizier et al. (2000) when feeding $345 \mathrm{mg} / \mathrm{d}$, while feeding MON at $24 \mathrm{mg} / \mathrm{kg}$ of DM (Bell et al., 2006) or $300 \mathrm{mg} / \mathrm{d}$ (Phipps et al., 2000) did not influence DMI of dairy cows. In contrast, Benchaar et al. (2006) demonstrated that MON supplementation at $33 \mathrm{mg} /$ $\mathrm{kg}$ of DM to beef cattle decreased the DMI, which is similar to the results of Sauer et al. (1998). Feeding MON in combination with OEO demonstrated no effect on DMI.

For many years, livestock producers (including those in China) have fed MON because of proven improvements in livestock performance and to be the benchmark to compare and contrast new nutritional technologies against. These data support the potential for using plant extracts to increase livestock production. To our knowledge, there are no published papers investigating the long-term OEO responses when fed to Holstein young bulls. There is limited information on the effects of the supplementation of EO, MON, and the mix of EO and MON for Holstein young bulls on growth performance, DMI, and feed efficiency. In the current study, the negative responses when feeding OEO and MON in combination provided no benefit for feeding a combination, but the individual main effects of feeding OEO or MON separately provided the basis of an opportunity for using OEO in the livestock production, especially AGP-free livestock production.

Blood measurements are an effective tool to gain insight into the metabolic mechanisms and health status of the animal (Tyler et al., 1999; Sporer et al., 2008; Klinkon and Ježek, 2012), but can be influenced by nutrition, inflammation, pregnancy, and lactation (Kaneko, 1997). A plethora of serum measurements were measured on collected blood samples for potentially elucidating the EO mechanism of action for 
enhancing growth performance. However, only BUN, albumin, triglycerides, and cholesterol concentrations were influenced by an interaction of OEO and MON or main effects of OEO or MON, and these responses are mostly related to DMI differences between treatments.

Protein status appears adequate because BUN concentrations tended to increase for bull calves fed OEO, which could be related to the greater DMI resulting in greater protein intake, but Zhou et al. (2020) reported that when using an in vitro system, OEO inclusion resulted in greater $\mathrm{CP}$ digestibility, which would contribute to the animal's protein status. In contrast, MON supplementation reduced BUN concentrations, which could be related to shifts in ruminal fermentation and microbial protein synthesis or increased utilization of blood amino acids for improving feed conversion (Anassori et al., 2017; Gupta, et al., 2019). In general, BUN and ALB concentrations may reflect protein and amino acid intake and protein catabolism (Whitaker et al., 1997; Klinkon and Ježek, 2012). Blood serum ALB concentrations were similar when feeding an EO containing thymol and other active components (Vendramini et al., 2016; Khateri et al., 2017), thus influencing ALB concentrations can be difficult.

An OEO by MON interaction was detected for serum TG and cholesterol concentrations for bull calves fed OEO or MON being greater than bulls fed the combination of OEO+MON or control. The reduction in DMI and lower feed conversion for bulls fed OEO+MON would have reduced energy available for TG storage and acetate as a precursor for cholesterol synthesis. Reports of OEO influencing lipid metabolism in young bulls are meager, but Vakili et al. (2013) reported that supplementation with thyme EO at $5 \mathrm{~g} / \mathrm{d}$ did not affect serum TG and $\mathrm{CHO}$ concentrations.

Feeding OEO and MON separately or in combination demonstrated no response in antioxidant status or immune function measurements, even though oregano has been reported to have antioxidant (Zou, et al., 2016; Cheng, et al., 2018) and immune function properties (Froehlich et al., 2017). Monensin at $21 \mathrm{mg} / \mathrm{kg}$ of DM has been reported to have no effect on oxidative stress (Jia et al., 2018), however OEO enhanced the immune system response against infectious diseases (Froehlich et al., 2017). Thus, absence of responses may indicate a lack of oxidative stress and immune function challenges (Halici et al., 2012).

\section{CONCLUSIONS}

This experiment demonstrated that feeding OEO or MON separately enhanced Holstein bull growth performance similarly. These data demonstrate that MON would be advantageous compared with OEO for improving feed efficiency. However, feeding OEO demonstrated other growth performance advantages for Holstein bulls compared with MON, thus feeding OEO could be a MON alternative, especially if AGP are a concern. It is unknown why feeding OEO and MON in combination is antagonistic to Holstein bull growth performance, but it is speculated to be related to ruminal propionate production. The recommendation is that these specific nutritional technologies should not be fed in combination to growing dairy cattle. However, feeding OEO can be used to feed antibiotic free livestock.

\section{ACKNOWLEDGMENTS}

The authors express appreciation to the farm staff and personnel at the Lintao Huajia Animal Husbandry Co. Ltd. (100 km south of Lanzhou, Gansu Province, China) in weighing and measuring bulls. The authors appreciate the assistance of the graduate students of the Gansu Agricultural University for the care and feeding of the animals and management assistance. The research team also acknowledges the financial support by 4 research grants from National Natural Science Foundation of China (\#31460592, Beijing, China), China's Agricultural Research System (CARS-39-18, Beijing, China), Agro-Scientific Research in the Public Interest (201503134, Beijing, China), and Gansu Academy of Agricultural Science Fund (2017GAAS30, Lanzhou, China). Lastly, the authors appreciate Ralco, Inc. (Marshall, MN) for supplying the Rum-A-Fresh product evaluated in this research. The authors certify that there is no conflict of interest or conflict of interest with any financial organization regarding the material presented and discussed in the manuscript.

\section{REFERENCES}

Adam, K., A. Sivropoulou, S. Kokkini, T. Lanaras, and M. Arsenakis. 1998. Antifungal activities of origanum vulgare ssp. hirtum, mentha spicata, lavandula angustifolia, and salvia fruticose essential oils against human pathogenic fungi. J. Agric. Food Chem. 46:17391745. https://doi.org/10.1021/jf9708296.

Aderinboye, R. Y., C. F. Onwuka, O. M. Arigbede, O. O. Oduguwa, and A. B. Aina. 2012. Effect of dietary monensin inclusion on performance, nutrient utilisation, rumen volatile fatty acid concentration and blood status of West African dwarf bucks fed with basal diets of forages. Trop. Anim. Health Prod. 44:1079-1087. https:// doi.org/10.1007/s11250-011-0043-7.

Al-Hijazeen, M. 2018. Effect of direct adding oregano essential oil (Origanum syriacum L.) on quality and stability of chicken meat patties. Food Sci. Technol. 38(Suppl. 1):123-130. https://doi.org/ 10.1590/1678-457x.17117.

Alexandratos, N., and J. Bruinsma. 2012. World Agriculture Towards 2030/2050: The 2012 Revision. ESA working paper no. 12-03. Food and Agriculture Organization of the United Nations, Rome, Italy.

Anassori, E., B. Dalir-Naghadeh, M. Valizadeh-Keshmeshtappeh, and S. Jafari. 2017. A comparative study on the efficacy of garlicon and monensin supplementation on blood metabolites and perfor- 
mance of fattening lambs. Livest. Sci. 199:74-78. https://doi.org/ 10.1016/j.livsci.2017.03.014.

AOAC International. 2019. Official Methods of Analysis. 21th ed. AOAC International, Rockville, MD.

Bakkali, F., S. Averbeck, D. Averbeck, and M. Idaomar. 2008. Biological effects of essential oils - A review. Food Chem. Toxicol. 46:446-475. https://doi.org/10.1016/j.fct.2007.09.106.

Bampidis, V. A., V. Christodoulou, P. Florou-Paneri, E. Christaki, A. B. Spais, and P. S. Chatzopoulou. 2005. Effect of dietary dried oregano leaves supplementation on performance and carcass characteristics of growing lambs. Anim. Feed Sci. Technol. 121:285295. https://doi.org/10.1016/j.anifeedsci.2005.02.002.

Beauchemin, K. A., and S. M. McGinn. 2006. Methane emissions from beef cattle: Effects of fumaric acid, essential oil, and canola oil. J. Anim. Sci. 84:1489-1496. https://doi.org/10.2527/2006.8461489x.

Bell, J. A., J. M. Griinari, and J. J. Kennelly. 2006. Effect of safflower oil, Flaxseed oil, monensin, and vitamin $\mathrm{E}$ on concentration of conjugated linoleic acid in bovine milk fat. J. Dairy Sci. 89:733-748. https://doi.org/10.3168/jds.S0022-0302(06)72135-X.

Benchaar, C. 2020. Feeding oregano oil and its main component carvacrol does not affect ruminal fermentation, nutrient utilization, methane emissions, milk production, or milk fatty acid composition of dairy cows. J. Dairy Sci. 103:1516-1527. https://doi.org/10 $.3168 /$ jds.2019-17230.

Benchaar, C., S. Calsamiglia, A. V. Chaves, G. R. Fraser, D. Colombatto, T. A. McAllister, and K. A. Beauchemin. 2008. A review of plant-derived essential oils in ruminant nutrition and production. Anim. Feed Sci. Technol. 145:209-228. https://doi.org/10.1016/j anifeedsci.2007.04.014.

Benchaar, C., J. L. Duynisveld, and E. Charmley. 2006. Effects of monensin and increasing dose levels of a mixture of essential oil compounds on intake, digestion and growth performance of beef cattle. Can. J. Anim. Sci. 86:91-96. https://doi.org/10.1002/rnc.697.

Burt, S. 2004. Essential oils: Their antibacterial properties and potential applications in foods - A review. Int. J. Food Microbiol. 94:223-253. https://doi.org/10.1016/j.ijfoodmicro.2004.03.022.

Calsamiglia, S., M. Busquet, P. W. Cardozo, L. Castillejos, and A. Ferret. 2007. Invited review: Essential oils as modifiers of rumen microbial fermentation. J. Dairy Sci. 90:2580-2595. https://doi . org/10.3168/jds.2006-644.

Castillejos, L., S. Calsamiglia, and A. Ferret. 2006. Effect of essential oil active compounds on rumen microbial fermentation and nutrient flow in in vitro systems. J. Dairy Sci. 89:2649-2658. https:// doi.org/10.3168/jds.S0022-0302(06)72341-4.

Cheng, C., M. Xia, X. Zhang, C. Wang, S. Jiang, and J. Peng. 2018. Supplementing oregano essential oil in a reduced-protein diet improves growth performance and nutrient digestibility by modulating intestinal bacteria, intestinal morphology, and antioxidative capacity of growing-finishing pigs. Animals (Basel) 8:159. https:// doi.org/10.3390/ani8090159.

Donabedian, S. M., L. A. Thal, E. Hershberger, M. B. Perri, J. W. Chow, P. Bartlett, R. Jones, K. Joyce, S. Rossiter, and K. Gay. 2003. Molecular characterization of gentamicin-resistant Enterococci in the United States: Evidence of spread from animals to humans through food. J. Clin. Microbiol. 41:1109-1113. https://doi .org/10.1128/JCM.41.3.1109-1113.2003 https://dor.org/10.1128/ JCM.41.3.1109-1113.

Dudko, P., A. Junkuszew, W. Bojar, M. Milerski, K. Szczepaniak, J. Le Scouarnec, J. Schmidová, K. Tomczuk, and M. Grzybek. 2018. Effect of dietary supplementation with preparation comprising the blend of essential oil from Origanum vulgare (lamiaceae) and Citrus spp. (citraceae) on coccidia invasion and lamb growth. Ital. J. Anim. Sci. 17:57-65. https://doi.org/10.1080/1828051X.2017 .1346965 .

Duffield, T. F., J. Merrill, and R. N. Bagg. 2012. Meta-analysis of the effects of monensin in beef cattle on feed efficiency, body weight gain ad dry matter intake. J. Anim. Sci. 90:4583-4592. https://doi .org/10.2527/jas.2011-5018.

Faul, F., E. Erdfelder, A. G. Lang, and A. Buchner. 2007. G*Power 3: a flexible statistical power analysis program for the social, behav- ioral, and biomedical sciences. Behav. Res. Methods 39:175-191. https://doi.org/10.3758/BF03193146.

Froehlich, K. A., K. W. Abdelsalam, C. Chase, J. Koppien-Fox, and D. P. Casper. 2017. Evaluation of essential oils and prebiotics for newborn dairy calves. J. Anim. Sci. 95:3772-3782. https://doi.org/ $10.2527 /$ jas2017.1601.

Fugita, C. A., R. M. do Prado, M. V. Valero, E. G. Bonafé, C. B. Carvalho, A. Guerrero, C. Sañudo, and I. N. do Prado. 2018. Effect of the inclusion of natural additives on animal performance and meat quality of crossbred bulls (Angus $\times$ Nellore) finished in feedlot. Anim. Prod. Sci. 58:2076-2083. https://doi.org/10.1071/ AN16242.

Gupta, S., M. Mohini, B. A. Malla, G. Mondal, and S. Pandita. 2019. Effects of monensin feeding on performance, nutrient utilisation and enteric methane production in growing buffalo heifers. Trop. Anim. Health Prod. 51:859-866. https://doi.org/10.1007/s11250 $-018-1766-5$

Halici, M., H. Imik, M. Koc, and R. Gumus. 2012. Effects of alphalipoic acid, vitamins $\mathrm{E}$ and $\mathrm{C}$ upon the heat stress in Japanese quails. J. Anim. Physiol. Anim. Nutr. (Berl.) 96:408-415. https:// doi.org/10.1111/j.1439-0396.2011.01156.x.

Hayirli, A., R. R. Grummer, E. V. Nordheim, and P. M. Crump. 2002 Animal and dietary factors affecting feed intake during the prefresh transition period in Holsteins. J. Dairy Sci. 85:3430-3443. https://doi.org/10.3168/jds.S0022-0302(02)74431-7.

He, Z. M., G. P. Li, and D. S. Zhu. 2016. Laboratory animals management and use guidelines. Mammalian Experimental Animals, Sheep. Science Press, Beijing, China.

Hristov, A. N., C. Lee, T. Cassidy, K. Heyler, J. A. Tekippe, G. A. Varga, B. Corl, and R. C. Brandt. 2013. Effect of Origanum vulgare L. leaves on rumen fermentation, production, and milk fatty acid composition in lactating dairy cows. J. Dairy Sci. 96:1189-1202. https://doi.org/10.3168/jds.2012-5975.

Jia, P., K. Cui, T. Ma, F. Wan, W. Wang, D. Yang, Y. Wang, B. Guo, L. Zhao, and Q. Diao. 2018. Influence of dietary supplementation with Bacillus licheniformis and Saccharomyces cerevisiae as alternatives to monensin on growth performance, antioxidant, immunity, ruminal fermentation and microbial diversity of fattening lambs. Sci. Rep. 8:16712. https://doi.org/10.1038/s41598-018 $-35081-4$.

Kaneko, J. J. 1997. Serum protein and the dysproteinemias. Pages 117-138 in Clinical Biochemistry of Domestic Animals. 5th ed. Academic Press, Cambridge, MA. https://doi.org/https://doi.org/10 .1016/B978-012396305-5/50006-3.

Khateri, N., O. Azizi, and H. Jahani-Azizabadi. 2017. Effects of a specific blend of essential oils on apparent nutrient digestion, rumen fermentation and rumen microbial populations in sheep fed a 50:50 alfalfa hay:concentrate diet. Asian-Australas. J. Anim. Sci. 30:370-378. https://doi.org/10.5713/ajas.15.0865.

Khiaosa-ard, R., and Q. Zebeli. 2013. Meta-analysis of the effects of essential oils and their bioactive compounds on rumen fermentation characteristics and feed efficiency in ruminants. J. Anim. Sci. 91:1819-1830. https://doi.org/10.2527/jas.2012-5691.

Klinkon, M., and J. Ježek. 2012. Values of Blood Variables in Calves. A Bird's-Eye View of Veterinary Medicine. InTech Press, Rijeka, Croatia.

Kolling, G. J., S. C. B. Stivanin, A. M. Gabbi, F. S. Machado, A. L. Ferreira, M. M. Campos, T. R. Tomich, C. S. Cunha, S. W. Dill, L. G. R. Pereira, and V. Fischer. 2018. Performance and methane emissions in dairy cows fed oregano and green tea extracts as feed additives. J. Dairy Sci. 101:4221-4234. https://doi.org/10.3168/ jds.2017-13841.

Lejonklev, J., U. Kidmose, S. Jensen, M. A. Petersen, A. L. F. Helwing, G. Mortensen, M. R. Weisbjerg, and M. K. Larsen. 2016. Short communication: Effect of oregano and caraway essential oils on the production and flavor of cow milk. J. Dairy Sci. 99:7898-7903. https://doi.org/10.3168/jds.2016-10910.

Meyer, N. F., G. E. Erickson, T. J. Klopfenstein, M. A. Greenquist, M. K. Luebbe, P. Williams, and M. A. Engstrom. 2009. Effect of essential oils, tylosin, and monensin on finishing steer performance, carcass characteristics, liver abscesses, ruminal fermentation, and 
digestibility. J. Anim. Sci. 87:2346-2354. https://doi.org/10.2527/ jas.2008-1493.

Mugnaini, L., S. Nardoni, L. Pistelli, M. Leonardi, L. Giuliotti, M. N. Benvenuti, F. Pisseri, and F. Mancianti. 2013. A herbal antifungal formulation of thymus serpillum, origanum vulgare and rosmarinus officinalis for treating ovine dermatophytosis due to trichophyton mentagrophytes. Mycoses 56:333-337. https://doi.org/10.1111/ myc. 12034

NRC. 2001. Nutrient Requirements of Dairy Cattle. 7th rev. ed. Natl. Acad. Press, Washington, DC.

Oba, M., and M. S. Allen. 2003. Intraruminal infusion of propionate alters feeding behavior and decrease energy intake of lactating dairy cows. J. Nutr. 133:1094-1099. https://doi.org/10.1093/jn/ 133.4.1094.

OJEU. 2003. Regulation (EC) No 1831/2003 of the European parliament and the Council of 22 September 2003 on Additives for Use in Animal Nutrition. Official Journal of European Union. Page L268/36 in OJEU of 10/18/2003.

Paraskevakis, N. 2018. Effects of dietary Greek oregano (origanum vulgare ssp. hirtum) supplementation on rumen fermentation, enzyme profile and microbial communities in goats. J. Anim. Physiol. Anim. Nutr. (Berl.) 102:701-705. https://doi.org/10.1111/jpn .12812 .

Patra, A. K. 2012. Enteric methane mitigation technologies for ruminant livestock: A synthesis of current research and future directions. Environ. Monit. Assess. 184:1929-1952. https://doi.org/10 $.1007 / \mathrm{s} 10661-011-2090-\mathrm{y}$.

Phipps, R. H., J. I. D. Wilkinson, L. J. Jonker, M. Tarrant, A. K. Jones, and A. Hodge. 2000. Effect of monensin on milk production of Holstein-Friesian dairy cows. J. Dairy Sci. 83:2789-2794. https: //doi.org/10.3168/jds.S0022-0302(00)75176-9.

Plaizier, J. C., A. Martin, T. Duffield, R. Bagg, P. Dick, and B. W. Mcbride. 2000. Effect of a prepartum administration of monensin in a controlled-release capsule on apparent digestibilities and nitrogen utilization in transition dairy cows. J. Dairy Sci. 83:29182925. https://doi.org/10.3168/jds.S0022-0302(00)75192-7.

Reverter, M., N. Bontemps, D. Lecchini, B. Banaigs, and P. Sasal. 2014. Use of plant extracts in fish aquaculture as an alternative to chemotherapy: Current status and future perspectives. Aquaculture 433:50-61. https://doi.org/10.1016/j.aquaculture.2014.05 .048 .

Rivaroli, D. C., R. M. Do Prado, M. G. Ornaghi, C. Mottin, T. R. Ramos, A. G. Barrado, A. M. Jorge, and I. N. Do Prado. 2017. Essential oils in the diet of crossbred (1/2 Angus vs. 1/2 Nellore) bulls finished in feedlot on animal performance, feed efficiency and carcass characteristics. J. Agric. Sci. 9:205-212. https://doi.org/10 .5539 /jas.v9n10p205.

Sauer, F. D., V. Fellner, R. Kinsman, J. K. Kramer, H. A. Jackson, A. J. Lee, and S. Chen. 1998. Methane output and lactation response in Holstein cattle with monensin or unsaturated fat added to the diet. J. Anim. Sci. 76:906-914. https://doi.org/10.2527/ 1998.763906x.

Simitzis, P. E., S. G. Deligeorgis, J. A. Bizelis, A. Dardamani, I. Theodosiou, and K. Fegeros. 2008. Effect of dietary oregano oil supplementation on lamb meat characteristics. Meat Sci. 79:217-223. https://doi.org/10.1016/j.meatsci.2007.09.005.

Sporer, K. R., L. Xiao, R. J. Tempelman, J. L. Burton, B. Earley, and M. A. Crowe. 2008. Transportation stress alters the circulating steroid environment and neutrophil gene expression in beef bulls. Vet. Immunol. Immunopathol. 121:300-320. https://doi.org/10 .1016/j.vetimm.2007.10.010.

Steele, R. G. D., and J. H. Torrie. 1980. Principles and Procedures of Statistics, 2nd ed. McGraw-Hill Co., New York, NY.
Tekippe, J. A., A. N. Hristov, K. S. Heyler, T. W. Cassidy, V. D. Zheljazkov, J. F. S. Ferreira, S. K. Karnati, and G. A. Varga. 2011. Rumen fermentation and production effects of Origanum vulgare L. leaves in lactating dairy cows. J. Dairy Sci. 94:5065-5079. https: //doi.org/10.3168/jds.2010-4095.

Tyler, J. W., S. M. Parish, T. E. Besser, D. C. Metre, G. M. Barrington, and J. R. Middleton. 1999. Detection of low serum immunoglobulin concentrations in clinically ill calves. J. Vet. Intern. Med. 13:40-43. https://doi.org/10.1111/j.1939-1676.1999.tb02163 .x.

Ultee, A., M. H. Bennik, and R. Moezelaar. 2002. The phenolic hydroxyl group of carvacrol is essential for action against the food-borne pathogen Bacillus cereus. Appl. Environ. Microbiol. 68:1561-1568. https://doi.org/10.1128/AEM.68.4.1561-1568.2002.

Unal, A., and N. Kocabagli. 2014. Effect of different dosages of oregano oil on performance and some blood parameters in lambs. Ankara Univ. Vet. Fak. Derg. 61:199-204. https://doi.org/10.1501/ Vetfak 0000002629.

Vakili, A. R., B. Khorrami, M. D. Mesgaran, and E. Parand. 2013. The effects of thyme and cinnamon essential oils on performance, rumen fermentation and blood metabolites in Holstein calves consuming high concentrate diet. Asian-Australas. J. Anim. Sci. 26:935-944. https://doi.org/10.5713/ajas.2012.12636.

Valero, M. V., R. M. Prado, F. Zawadzki, C. E. Eiras, G. S. Madrona, and I. N. Prado . 2014. Propolis and essential oils additives in the diets improved animal performance and feed efficiency of bulls finished in feedlot. Acta Sci. Anim. Sci. 36:419-426. https://doi.org/ 10.4025/actascianimsci.v36i4.23856.

Van Boeckel, T. P., E. E. Glennon, D. Chen, M. Gilbert, T. P. Robinson, B. T. Grenfell, S. A. Levin, S. Bonhoeffer, and R. Laxminarayan. 2017. Reducing antimicrobial use in food animals. Science 357:1350-1352. https://doi.org/10.1126/science.aao1495.

van den Bogaard, A. E., N. Bruinsma, and E. E. Stobberingh. 2000. The effect of banning avoparcin on VRE carriage in the Netherlands. J. Antimicrob. Chemother. 46:146-148. https://doi.org/10 $.1093 / \mathrm{jac} / 46.1 .146$.

Vendramini, T. H. A., C. S. Takiya, T. H. Silva, F. Zanferari, M. F. Rentas, J. C. Bertoni, C. E. C. Consentini, R. Gardinal, T. S. Acedo, and F. P. Rennó. 2016. Effects of a blend of essential oils, chitosan or monensin on nutrient intake and digestibility of lactating dairy cows. Anim. Feed Sci. Technol. 214:12-21. https://doi .org/10.1016/j.anifeedsci.2016.01.015.

Whitaker, D. A., H. F. Eayres, K. Aitchison, and J. M. Kelly. 1997. No effect of a dietary zinc proteinate on clinical mastitis, infection rate, recovery rate and somatic cell count in dairy cows. Vet. J. 153:197-203. https://doi.org/10.1016/S1090-0233(97)80040-8.

Wu, J., J. Guo, T. Liu, H. Chen, Y. Bai, and D. P. Casper. 2020. Feeding a calf starter containing monensin alone or in combination with an oregano, prebiotics, and cobalt blend to Holstein calves. J. Anim. Sci. 98. In press.

Zhang, W., S. Xiao, H. Samaraweera, E. J. Lee, and D. U. Ahn. 2010. Improving functional value of meat products. Meat Sci. 86:15-31. https://doi.org/10.1016/j.meatsci.2010.04.018.

Zhou, R., J. Wu, X. Lang, L. Liu, D. P. Casper, C. Wang, L. Zhang, and S. Wei. 2019. Oregano's impact on in vitro ruminal fermentation, methane production and ruminal microbial community. J. Dairy Sci. 103:2303-2314.

Zou, Y., J. Wang, J. Peng, and H. Wei. 2016. Oregano essential oil induces SOD1 and GSH expression through Nrf2 activation and alleviates hydrogen peroxide-induced oxidative damage in IPECJ2 cells. Oxid. Med. Cell. Longev. 2016:1-13. https://doi.org/10 $.1155 / 2016 / 5987183$ 